\title{
The safety and tolerability of cariprazine in long-term treatment of schizophrenia: a post hoc pooled analysis
}

Henry A. Nasrallah ${ }^{1 *}$, Willie Earley², Andrew J. Cutler ${ }^{3}$, Yao Wang ${ }^{2}$, Kaifeng Lu², István Laszlovszky ${ }^{4}$, György Németh ${ }^{4}$ and Suresh Durgam²

\begin{abstract}
Background: Schizophrenia is a chronic and debilitating neuropsychiatric disorder that often requires long-term pharmacotherapy to manage symptoms and prevent relapse. Cariprazine is a potent dopamine $D_{3}$ and $D_{2}$ receptor partial agonist that is FDA-approved in the US for the treatment of schizophrenia and manic or mixed episodes associated with bipolar I disorder in adults; the recommended dose range is $1.5-6 \mathrm{mg} / \mathrm{d}$.

Methods: To further characterize the long-term safety of cariprazine, data from two 48-week open-label, flexible-dose extension studies were pooled for post hoc analyses. Outcomes were evaluated in the pooled safety population (patients who received $\geq 1$ dose of cariprazine during an open-label extension period); findings were summarized using descriptive statistics for the overall cariprazine group and in modal daily dose groups $(1.5-3,4.5-6$, and $9 \mathrm{mg} / \mathrm{d})$.

Results: Of the 679 patients in the overall cariprazine safety population, $40.1 \%$ completed the study. The only adverse events (AEs) leading to discontinuation of $\geq 2 \%$ of patients in any dose group were akathisia, worsening of schizophrenia, and psychotic disorder. Treatment-emergent AEs (TEAEs) of akathisia, insomnia, weight increased, and headache were reported in $\geq 10 \%$ of the overall population. Mean prolactin levels decreased in all dose groups (overall, $-15.4 \mathrm{ng} / \mathrm{mL}$ ). Clinically insignificant changes in aminotransferase levels and alkaline phosphatase were observed; no dose-response relationship was observed across groups. Mean total ( $-5.3 \mathrm{mg} / \mathrm{dL}$ ), low-density lipoprotein $(-3.5 \mathrm{mg} / \mathrm{dL})$, and high-density lipoprotein $(-0.8 \mathrm{mg} / \mathrm{dL})$ cholesterol levels decreased; no dose-response relationship was observed for metabolic parameters. Mean change in body weight was $1.58 \mathrm{~kg}$; body weight increase and decrease $\geq 7 \%$ occurred in $27 \%$ and $11 \%$ of patients, respectively. Mean changes in cardiovascular parameters, including blood pressure and pulse, were generally not considered clinically significant. EPS-related TEAEs that occurred in $\geq 5 \%$ of patients were akathisia, tremor, restlessness, and extrapyramidal disorder.
\end{abstract}

Conclusion: In these post hoc pooled analyses of data from 2 long-term open-label studies, treatment with cariprazine was generally safe and well tolerated. Results support the safety and tolerability of cariprazine within the FDA-recommended dose range of $1.5-6 \mathrm{mg} / \mathrm{d}$ for schizophrenia.

Clinical trials registration: NCT01104792, NCT00839852.

Keywords: Cariprazine, Schizophrenia, Long-term safety, Atypical antipsychotic, Post hoc analysis, Open-label

\footnotetext{
* Correspondence: hnasral@slu.edu

'Saint Louis University, 1438 South Grand Blvd., Suite 105, St. Louis, MO

63104, USA

Full list of author information is available at the end of the article
} International License (http://creativecommons.org/licenses/by/4.0/), which permits unrestricted use, distribution, and reproduction in any medium, provided you give appropriate credit to the original author(s) and the source, provide a link to the Creative Commons license, and indicate if changes were made. The Creative Commons Public Domain Dedication waiver (http://creativecommons.org/publicdomain/zero/1.0/) applies to the data made available in this article, unless otherwise stated. 


\section{Background}

Schizophrenia is a chronic and debilitating neuropsychiatric disorder with high rates of medical morbidity and mortality [1]. To manage symptoms and prevent relapse, long-term pharmacotherapy is often required [2]. Antipsychotic drugs, which are the foundation of treatment in schizophrenia, differ in many properties and cannot therefore be easily categorized by first- or secondgeneration distinctions [3]. Even antipsychotics introduced since clozapine (ie, the atypical antipsychotics) do not share a similar class-related pharmacologic profile [4]. Although only small differences in efficacy have been observed among antipsychotic agents in clinical trials, there is variability in individual patient response, as well as in the side effect and tolerability profiles [3]. These factors warrant careful consideration when choosing an antipsychotic treatment.

While first-generation agents are associated with high risk of extrapyramidal symptoms (EPS) and sustained prolactin elevation, second-generation agents have shown a propensity for other important adverse effects including weight gain, metabolic and cardiac abnormalities, somnolence, and sedation $[5,6]$. Understanding the side effect profile of an antipsychotic is critical since efficacy can only be viewed within the context of tolerability and the ability of the patient to remain on treatment. In this vein, poor tolerability has been identified as a barrier to medication adherence for patients with schizophrenia [7], and medication nonadherence is associated with considerable consequences including greater risk of relapse, longer time to remission, hospitalization, and attempted suicide [8].

Cariprazine is a potent dopamine $D_{3}$ and $D_{2}$ receptor partial agonist with preferential binding to $D_{3}$ receptors; it is FDA-approved in the United States for the treatment of schizophrenia $(1.5-6 \mathrm{mg} / \mathrm{d})$ and manic or mixed episodes associated with bipolar I disorder $(3-6 \mathrm{mg} / \mathrm{d}$ ) in adults. Cariprazine has demonstrated preferential binding to $D_{3}$ receptors in vitro [9], and it has shown high in vivo occupancy of both $D_{3}$ and $D_{2}$ receptors at antipsychotic-effective doses in rats [10] and in clinically active dose ranges in patients with schizophrenia [11]. Other atypical antipsychotics, such as aripiprazole, clozapine, olanzapine, and risperidone, show varying levels of in vitro affinity for $\mathrm{D}_{3}$ receptors, but fail to show substantial in vivo $D_{3}$ receptor occupancy in patients at clinically relevant doses [12-14]. Cariprazine also acts as an antagonist at serotonin $5-\mathrm{HT}_{2 \mathrm{~B}}$ receptors and as a partial agonist at $5-\mathrm{HT}_{1 \mathrm{~A}}$ receptors, with lower affinity for $5-\mathrm{HT}_{2 \mathrm{~A}}, 5-\mathrm{HT}_{2 \mathrm{C}}$, histamine $\mathrm{H}_{1}$, and adrenergic $\alpha_{1}$ receptors and negligible affinity at other receptors [9]. This receptor binding profile may provide potential tolerability benefits since some negative side effects, such as sedation and weight gain, have been associated with affinity at the $5-\mathrm{HT}_{2 \mathrm{C}}$ and $\mathrm{H}_{1}$ receptors [15-17], and some cardiovascular AEs may be associated with affinity at adrenergic $\alpha_{1}$ receptors [18]. Of note, cariprazine has a complex pharmacokinetic profile, with 2 major active metabolites, desmethyl cariprazine and didesmethyl cariprazine, and a long effective half-life for the total active moieties [19].

The short-term safety and efficacy of cariprazine in schizophrenia have been demonstrated in 3 randomized, 6-week, double-blind, placebo-controlled, phase II (RGH-MD-16) and phase III (RGH-MD-04 and RGH-MD-05) clinical trials [20-22]; active comparators to assess assay sensitivity were used in RGH-MD-16 (risperidone) and RGH-MD-04 (aripiprazole). The long-term safety and tolerability of cariprazine has been evaluated in two 48-week, open-label, flexible-dose extension studies (RGH-MD-11 [NCT01104792] and RGHMD-17 [NCT00839852]) [23, 24]. Study RGH-MD-11 included rollover patients from the short-term lead-in studies (RGH-MD-04 and RGH-MD-05) as well as newly enrolled patients, while study RGH-MD-17 only included rollover patients from RGH-MD-16. To further characterize the long-term safety of cariprazine, data from these extension studies were pooled for post hoc analyses.

\section{Methods}

The protocols of the constituent studies included in these pooled post hoc analyses were approved by an institutional review board or ethics committee and the studies were conducted in compliance with guidelines for good clinical practice; all patients gave informed written consent to participate.

Since the long-term studies included in these analyses were flexibly dosed, this post hoc investigation evaluated safety and tolerability parameters in both the overall pooled population and in patient subgroups based on modal daily dose (the most frequently used dose during the study). Modal daily dose groups allowed us to assess long-term cariprazine exposure and the potential for doseresponse relationships in various safety parameters within the FDA-recommended dose range. The modal daily dose groups that were evaluated in these investigations were cariprazine $1.5-3 \mathrm{mg} / \mathrm{d}, 4.5-6 \mathrm{mg} / \mathrm{d}$, and $9 \mathrm{mg} / \mathrm{d}$.

\section{Study design}

Results from 2 long-term, open-label, flexible-dose studies were pooled for these analyses. In RGH-MD-11, cariprazine was administered in a range of $3-9 \mathrm{mg} / \mathrm{d}$ and in RGH-MD-17, the dose range was $1.5-4.5 \mathrm{mg} / \mathrm{d}$. Each study was 53 weeks in duration, consisting of a no-drug screening period of up to 7 days, a 48-week open-label flexible-dose cariprazine treatment period, and a 4-week safety follow-up period. Cariprazine was initiated at $1.5 \mathrm{mg} / \mathrm{d}$ on day 1 of both studies. In RGH-MD-11, 1.5mg dose increases could be made on days 2,3 , and 5 , and on day 8 , a 3-mg increase could be made to the 
maximum $9 \mathrm{mg} / \mathrm{d}$ dose. In RGH-MD-17, 1.5-mg dose increases could be made on days 2 and 3 to reach the $4.5 \mathrm{mg} / \mathrm{d}$ maximum dose. Doses were increased only if response was inadequate and there were no tolerability issues; dosage could be decreased by $1.5-\mathrm{mg} / \mathrm{d}$ increments at any time due to tolerability issues.

In both studies, all patients were hospitalized during the first week of open-label treatment; thereafter, patients remained hospitalized for an additional 1 or 2 weeks at the discretion of the investigator or they were discharged and followed-up as outpatients. In the event of clinical deterioration, outpatients could be rehospitalized for safety reasons. For patients who completed a lead-in study, the medical, psychiatric, and medication histories obtained at the first lead-in study visit were used in the extension.

\section{Inclusion criteria}

All patients who participated in the long-term safety studies were 18 to 60 years of age, inclusive, and had a current Diagnostic and Statistical Manual of Mental Disorders, Fourth Edition, Text Revision (DSM-IV-TR) [25] diagnosis of schizophrenia for a minimum of 1 year. Participants had normal physical examination, clinical laboratory, vital sign, and electrocardiogram (ECG) results or abnormal results that were not considered clinically significant; female patients of childbearing age were not pregnant or breastfeeding. In RGH-MD-11, patients had either completed 6 weeks of double-blind treatment in a lead-in study (RGH-MD-04 [20] or RGHMD-05 [22]) or were newly enrolled patients; all patients were required to have a score $\leq 25$ on the Positive and Negative Syndrome Scale (PANSS) [26] positive subscale score (PANSS items P1 to P7) and a score $\leq 3$ on the Clinical Global Impressions-Severity of Illness (CGI-S) [27]. In RGH-MD-17, eligible patients had completed 6 weeks of double-blind treatment in lead-in study RGH-MD-16 [21] and responded to treatment (CGI-S score $\leq 3$ and PANSS total score reduction $\geq 20 \%$ from lead-in study baseline). Patients had a designated caregiver to attend study visits with them or provide written documentation verifying medication compliance.

\section{Exclusion criteria}

Typical exclusion criteria for clinical trials in schizophrenia were applied. Briefly, patients were excluded if they had various psychiatric diagnoses other than schizophrenia (eg, other psychotic disorders, bipolar disorder, cognitive disorders, or alcohol or substance abuse or dependence [with the exception of nicotine or caffeine dependence] within 3 months of the study). Patients with treatment-resistant schizophrenia (no symptomatic response to at least 2 antipsychotic trials of adequate dose and duration), suicide risk (ie, attempt within past
2 years or investigator judged), and a first psychotic episode were also excluded. Additionally, patients were excluded for any concurrent medical condition that may have interfered with the conduct of the study, confounded the interpretation of the study results, or endangered the patient's well being. Existing issues related to safety and tolerability including clinically significant, uncontrolled adverse events (AEs), EPS that were not adequately controlled by EPS medications, and various ophthalmology assessment criteria were exclusionary. Patients who required concomitant treatment with prohibited medications including psychotropic drugs were excluded; lorazepam (for agitation, irritability, hostility, and restlessness), eszopiclone, zolpidem, zolpidem extended release, chloral hydrate, or zaleplon (for insomnia), and diphenhydramine, benztropine or equivalent, or propranolol (for EPS or akathisia) were allowed.

\section{Outcome assessments}

The long-term safety and tolerability of cariprazine were the primary objectives of the extension studies. Safety parameters included AEs, vital signs, clinical laboratory tests, ECGs, physical examinations, and ophthalmologic examinations. Suicidality was assessed using the Columbia-Suicide Severity Rating Scale (C-SSRS) [28] in RGH-MD-11 and the Suicidality Tracking Scale (STS) [29] in RGH-MD-17. EPS and movement disorders were evaluated by $\mathrm{AE}$ reports and rating scale assessments: Barnes Akathisia Rating Scale (BARS), [30] Abnormal Involuntary Movement Scale (AIMS), [31] and SimpsonAngus Scale (SAS) [32].

Pooled PANSS findings summarized changes in the symptoms of schizophrenia. Although no efficacy conclusions can be made based on changes in PANSS because of the lack of a comparator group in this open-label study, it is of note that increased (worse) PANSS scores could indicate a worsening of the clinical condition and could also be evaluated as a safety concern.

\section{Data analysis}

Safety analyses were performed on the safety population, which consisted of patients who received at least one dose of cariprazine during the open-label extension period; findings were summarized using descriptive statistics for the overall cariprazine group and in modal daily dose groups $(1.5-3,4.5-6$, and $9 \mathrm{mg} / \mathrm{d})$. Analysis of modal daily dose groups were conducted to evaluate potential dose-response relationships in safety parameters. For patients continuing from a lead-in study, the lead-in study safety baseline was used as the baseline for all analyses of safety parameters; for new patients (RGH-MD11), the baseline was the last value before the first dose of open-label cariprazine. 
AEs were classified by the preferred term. For patients who completed a lead-in study, an AE that started during open-label treatment was considered a treatmentemergent adverse event (TEAE) if it was not present before the first dose of double-blind treatment in the leadin study or if it increased in intensity after the first dose of open-label treatment. For new patients, an AE that started during open-label treatment was considered a TEAE if it was not present before the first dose of open-label treatment or if it increased in intensity after the first dose of open-label treatment.

In the studies that were pooled, efficacy assessments were collected but not categorized as primary, secondary, or additional. Change from baseline to end of treatment in PANSS total score was summarized using descriptive statistics; no inferential statistics were performed.

\section{Results}

\section{Patient disposition and demographics}

There were 679 patients in the pooled safety population; 586 patients were from RGH-MD-11 and 93 were from RGH-MD-17. Of these patients, 416 had not previously been exposed to cariprazine, having either received placebo or an active comparator in a lead-in study, or enrolling directly into RGH-MD-11 as a new patient. Completion rates were higher in the $1.5-3$ and $4.5-6 \mathrm{mg} / \mathrm{d}$ modal daily dose groups than in the $9 \mathrm{mg} / \mathrm{d}$ modal daily dose group (Table 1). The most frequent reason for discontinuation in any group was withdrawal of consent, which occurred at a similar incidence across doses; discontinuation due to AEs was highest in the $9 \mathrm{mg} / \mathrm{d}$ and $1.5-3 \mathrm{mg} / \mathrm{d}$ dose groups.

The demographic and baseline characteristics of the safety population are presented in Table 2.

\section{Safety and tolerability findings Extent of exposure}

Mean (SD) duration of treatment was 188.4 (136.8) days in the overall cariprazine group; treatment duration was longest in 4.5-6 mg/d dose group (201.2 [133.7] days) and similar in the $1.5-3 \mathrm{mg} / \mathrm{d}$ (174.1 [147.6] days) and $9 \mathrm{mg} / \mathrm{d}$ (173.8 [129.1] days) groups. The overall mean daily dose of cariprazine was $5.42 \mathrm{mg}$; in the $1.5-3 \mathrm{mg} / \mathrm{d}$, $4.5-6 \mathrm{mg} / \mathrm{d}$, and $9 \mathrm{mg} / \mathrm{d}$ dose groups it was $3.08 \mathrm{mg}$, $5.46 \mathrm{mg}$, and $7.97 \mathrm{mg}$, respectively. The overall modal daily dose for patients in the $1.5-3 \mathrm{mg}$ modal daily dose group was $1.5 \mathrm{mg} / \mathrm{d}$ for $13(7.6 \%)$ patients and $3 \mathrm{mg} / \mathrm{d}$ for 157 (92.4\%) patients; the overall modal daily dose for patients in the $4.5-6 \mathrm{mg} / \mathrm{d}$ modal daily dose group was $4.5 \mathrm{mg} / \mathrm{d}$ for 63 (17.5\%) patients and $6 \mathrm{mg} / \mathrm{d}$ for 298 (82.5\%) patients; the overall modal daily dose was $9 \mathrm{mg} / \mathrm{d}$ for all 148 patients in the 9-mg/d group. Patient-years exposure (total amount of time exposed to open-label cariprazine, expressed in years) was 350.3 years.

\section{Adverse events}

Two deaths occurred during the open-label cariprazine studies; neither event was considered related to treatment. In RGH-MD-17, 1 death from suicide occurred in the cariprazine $4.5-6 \mathrm{mg} / \mathrm{d}$ dose group (day 327 of treatment); the patient had no history of suicidality and no trigger event was identified. In RGH-MD-11, 1 death from cardiac hypertrophy of unknown etiology occurred 3 days after the initial screening in a newly enrolled patient who had not received study drug; the patient had normal ECG findings at screening and no history of chest pain.

A summary of TEAEs is presented in Table 3. The only AEs that led to discontinuation of $\geq 2 \%$ of patients in any dose group were akathisia, worsening of schizophrenia, and psychotic disorder. Of patients with TEAEs that resulted in discontinuation, $80.3 \%$ had events that resolved; the median time to resolution of TEAEs was 12 days overall $(1.5-3 \mathrm{mg} / \mathrm{d}=11$ days; $4.5-6 \mathrm{mg} / \mathrm{d}=14$ days; $9 \mathrm{mg} / \mathrm{d}=14$ days). TEAEs of akathisia, insomnia, headache, and weight increased were each reported in $\geq 10 \%$ of patients overall (Table 3). An inverse

Table 1 Patient Disposition (Safety Population)

\begin{tabular}{|c|c|c|c|c|}
\hline & $\begin{array}{l}\text { Cariprazine } \\
1.5-3 \mathrm{mg} / \mathrm{d} \\
n=170\end{array}$ & $\begin{array}{l}\text { Cariprazine } \\
4.5-6 \mathrm{mg} / \mathrm{d} \\
n=361\end{array}$ & $\begin{array}{l}\text { Cariprazine } \\
9 \mathrm{mg} / \mathrm{d} \\
n=148\end{array}$ & $\begin{array}{l}\text { Cariprazine } \\
\text { Overall } \\
N=679 \\
\end{array}$ \\
\hline Completed, n (\%) & $70(41.2)$ & $154(42.7)$ & $48(32.4)$ & $272(40.1)$ \\
\hline \multicolumn{5}{|l|}{ Reasons for discontinuation, n (\%) } \\
\hline Adverse event & $28(16.5)$ & $29(8.0)$ & $26(17.6)$ & $83(12.2)$ \\
\hline Insufficient therapeutic response & $1(0.6)$ & $11(3.0)$ & $13(8.8)$ & $25(3.7)$ \\
\hline Protocol violation & $13(7.6)$ & $31(8.6)$ & $10(6.8)$ & $54(8.0)$ \\
\hline Withdrawal of consent & $44(25.9)$ & $88(24.4)$ & $38(25.7)$ & $170(25.0)$ \\
\hline Lost to follow-up & $11(6.5)$ & $29(8.0)$ & $10(6.8)$ & $50(7.4)$ \\
\hline Other reasons & $3(1.8)$ & $19(5.3)$ & $3(2.0)$ & $25(3.7)$ \\
\hline Entered safety follow-up, (n)\% & $121(71.2)$ & $234(64.8)$ & $102(68.9)$ & $457(67.3)$ \\
\hline
\end{tabular}


Table 2 Patient Demographic and Baseline Characteristics (Safety Population)

\begin{tabular}{|c|c|c|c|c|}
\hline Patient Demographic and Schizophrenia Characteristics & $\begin{array}{l}\text { Cariprazine } \\
1.5-3 \mathrm{mg} / \mathrm{d} \\
n=170\end{array}$ & $\begin{array}{l}\text { Cariprazine } \\
4.5-6 \mathrm{mg} / \mathrm{d} \\
n=361\end{array}$ & $\begin{array}{l}\text { Cariprazine } \\
9 \mathrm{mg} / \mathrm{d} \\
n=148\end{array}$ & $\begin{array}{l}\text { Cariprazine } \\
\text { Overall } \\
N=679\end{array}$ \\
\hline Age, mean (SD), years & $40.2(10.6)$ & $37.9(10.8)$ & $38.0(11.2)$ & $38.5(10.9)$ \\
\hline Male, n (\%) & $123(72.4)$ & $249(69.0)$ & $99(66.9)$ & $471(69.4)$ \\
\hline \multicolumn{5}{|l|}{ Race, n (\%) } \\
\hline White & $71(41.8)$ & $174(48.2)$ & $57(38.5)$ & $302(44.5)$ \\
\hline Black & $64(37.6)$ & $116(32.1)$ & $60(40.5)$ & $240(35.3)$ \\
\hline Asian & $17(10.0)$ & $57(15.8)$ & $24(16.2)$ & $98(14.4)$ \\
\hline Other & $8(4.7)$ & $10(2.8)$ & $6(4.1)$ & $24(3.5)$ \\
\hline Missing ${ }^{a}$ & $10(5.9)$ & $4(1.1)$ & $1(0.7)$ & $15(2.2)$ \\
\hline Weight, mean (SD), kg & $79.26(19.15)$ & $77.13(19.15)$ & $82.69(22.81)$ & $78.88(20.09)$ \\
\hline Body mass index (BMI), mean (SD), kg/m² & $26.96(5.56)$ & $26.32(5.43)$ & $27.82(6.26)$ & $26.81(5.68)$ \\
\hline Duration of schizophrenia, mean (SD), years & $12.9(10.0)$ & $11.4(9.5)$ & $13.5(9.9)$ & $12.2(9.8)$ \\
\hline Age at onset, mean (SD), years & $27.2(9.4)$ & $26.4(9.2)$ & $24.4(8.6)$ & $26.2(9.1)$ \\
\hline
\end{tabular}

${ }^{a}$ Race data were not collected in patients from Romania in study RGH-MD-11 per local regulations

dose-response relationship was seen for akathisia, which may be due to patient selection bias since patients who did not tolerate lower doses of cariprazine would be unlikely to up-titrate to a higher dose level. Likewise, patients that developed tolerability concerns at higher doses were down-titrated and remained on lower doses where tolerability was improved. Anxiety and tremor were reported in $\geq 10 \%$ of patients in one of the dose groups that is within the FDA-recommended dose range for schizophrenia $(1.5-6 \mathrm{mg} / \mathrm{d})$; schizophrenia was reported in $\geq 10 \%$ of patients in the $9 \mathrm{mg} / \mathrm{d}$ dose group (10.8\%). Somnolence was reported in $26(3.8 \%)$ patients overall $(1.5-3 \mathrm{mg} / \mathrm{d}=6$ [3.5\%] patients; $4.5-6 \mathrm{mg} / \mathrm{d}=11$ [3.0\%]; $9 \mathrm{mg} / \mathrm{d}=6[6.1 \%]$ ); sedation was reported in 21 (3.1\%) patients overall $(1.5-3 \mathrm{mg} / \mathrm{d}=7$ [4.1\%] patients; $4.5-6 \mathrm{mg} / \mathrm{d}=11$ [3.0\%]; $9 \mathrm{mg} / \mathrm{d}=3$ [2.0\%]). Overall, AEs were considered mild or moderate in $71.1 \%$ of patients $(1.5-3 \mathrm{mg} / \mathrm{d}=74.1 \%$; $4.5-6 \mathrm{mg} / \mathrm{d}=70.1 \%$; $9 \mathrm{mg} / \mathrm{d}=70.3 \%)$ and related to treatment in $59.6 \%$ of patients $(1.5-3 \mathrm{mg} / \mathrm{d}=113$ [66.5\%] patients; $4.5-6 \mathrm{mg} / \mathrm{d}=204$ [56.5\%]; $9 \mathrm{mg} / \mathrm{d}=88$ [59.5\%]).

The most commonly reported serious AEs (SAEs) were worsening of schizophrenia (30 [4.4\%] patients) and psychotic disorder (14 [2.1\%] patients). In the 1.5$3 \mathrm{mg} / \mathrm{d}, 4.5-6 \mathrm{mg} / \mathrm{d}$, and $9 \mathrm{mg} / \mathrm{d}$ modal daily dose groups, SAEs of schizophrenia (worsening of symptoms) occurred in $8(4.7 \%)$ patients, $12(3.3 \%)$ patients, and 10 (6.8\%) patients, respectively; SAEs of psychotic disorder occurred in $2(1.2 \%)$ patients, $5(1.4 \%)$ patients, and 7 (4.7\%) patients, respectively.

\section{Extrapyramidal symptoms}

Extrapyramidal symptoms were evaluated by AEs and rating scale assessments (Table 4). The EPS-related TEAEs (see footnote in Table 4) that occurred in $\geq 5 \%$ of patients were akathisia, tremor, restlessness, and extrapyramidal disorder. EPS-related TEAEs other than akathisia/restlessness were reported in $135(19.9 \%)$ patients $(1.5-3 \mathrm{mg} / \mathrm{d}=46$ [27.1\%] patients; $4.5-6 \mathrm{mg} / \mathrm{d}=58$ [16.1\%]; $9 \mathrm{mg} / \mathrm{d}=31$ [20.9\%]). Tardive dyskinesia was reported in 2 patients $(1.5-3 \mathrm{mg} / \mathrm{d}=1[0.1 \%] ; 4.5-6 \mathrm{mg} / \mathrm{d}=1[0.1 \%])$. The majority of patients with any EPS-related AEs had events that were considered mild or moderate in cariprazine overall $(97.7 \%)$ and in each modal daily dose group $(1.5-3 \mathrm{mg} / \mathrm{d}=96.0 \% ; 4.5-6 \mathrm{mg} / \mathrm{d}=99.0 \%$; $9 \mathrm{mg} / \mathrm{d}=98.0 \%)$.

Akathisia/restlessness was reported in 133 (19.6\%) patients $(1.5-3 \mathrm{mg} / \mathrm{d}=48$ [28.2\%] patients; $4.5-6 \mathrm{mg} /$ $\mathrm{d}=58$ [16.1\%]; $9 \mathrm{mg} / \mathrm{d}=27$ [18.2\%]). Most akathisia/ restlessness was considered mild or moderate overall $(97.8 \%)$ and resulted in few study discontinuations overall (6 [0.9\%] patients) or in any modal dose group $(1.5-3 \mathrm{mg} / \mathrm{d}=5$ [2.9\%] patients; $4.5-6 \mathrm{mg} / \mathrm{d}=1$ $[0.3 \%] ; 9 \mathrm{mg} / \mathrm{d}=0)$. The vast majority of akathisia TEAEs occurred in the first 6 weeks of treatment $(1.5-3.0 \mathrm{mg} / \mathrm{d}=42$ cases; $4.5-6 \mathrm{mg} / \mathrm{d}=46$ cases; $9 \mathrm{mg} / \mathrm{d}=18$ cases); from weeks 7 to 48 , the total number of first-time akathisia events decreased dramatically $(1.5-3.0 \mathrm{mg} / \mathrm{d}=6$ cases; $4.5-6 \mathrm{mg} / \mathrm{d}=12$ cases; $9 \mathrm{mg} / \mathrm{d}=9$ cases). Overall, the median time to resolution of akathisia/restlessness after the last dose of cariprazine was 15 days $(1.5-3.0 \mathrm{mg} / \mathrm{d}=24$ days; $4.5-6 \mathrm{mg} / \mathrm{d}=8$ days; $9 \mathrm{mg} / \mathrm{d}=11$ days) and there were no SAEs of akathisia, restlessness, or EPS. Medication was used to manage akathisia/restlessness by the majority of cariprazine patients: 48/89 [53.9\%] patients with mild akathisia/restlessness, 28/41 [68.3\%] patients with moderate akathisia/restlessness, and $2 / 3$ [66.7\%]) patients with severe akathisia/restlessness. 
Table 3 Treatment-Emergent Adverse Events During Open-Label Treatment (Safety Population)

\begin{tabular}{|c|c|c|c|c|}
\hline Summary of Adverse Events & $\begin{array}{l}\text { Cariprazine } \\
1.5-3 \mathrm{mg} / \mathrm{d} \\
n=170 \\
\mathrm{n}(\%)\end{array}$ & $\begin{array}{l}\text { Cariprazine } \\
4.5-6 \mathrm{mg} / \mathrm{d} \\
n=361 \\
\mathrm{n}(\%)\end{array}$ & $\begin{array}{l}\text { Cariprazine } \\
9 \mathrm{mg} / \mathrm{d} \\
n=148 \\
\mathrm{n}(\%)\end{array}$ & $\begin{array}{l}\text { Cariprazine } \\
\text { Overall } \\
N=679 \\
\mathrm{n}(\%)\end{array}$ \\
\hline Patients with $\geq 1$ TEAE & $141(82.9)$ & $287(79.5)$ & $127(85.8)$ & $555(81.7)$ \\
\hline Patients with $\geq 1$ SAE & $17(10.0)$ & $37(10.2)$ & $28(18.9)$ & $82(12.1)$ \\
\hline Deaths & 0 & $1(0.3)$ & 0 & $1(0.1)$ \\
\hline AEs leading to discontinuations & $28(16.5)$ & $29(8.0)$ & $27(18.2)^{\mathrm{a}}$ & $84(12.4)$ \\
\hline \multicolumn{5}{|c|}{ AEs leading to study discontinuation in $>2 \%$ in any group } \\
\hline Akathisia & $4(2.4)$ & $1(0.3)$ & 0 & $5(0.7)$ \\
\hline Schizophrenia & $5(2.9)$ & $7(1.9)$ & $9(6.1)$ & $21(3.1)$ \\
\hline Psychotic disorder & $2(1.2)$ & $3(0.8)$ & $8(5.4)$ & $13(1.9)$ \\
\hline \multicolumn{5}{|c|}{ Incidence of common TEAEs ( $\geq 5 \%$ in any group) } \\
\hline Akathisia & $40(23.5)$ & $45(12.5)$ & $20(13.5)$ & 105 (15.5) \\
\hline Insomnia & $22(12.9)$ & $43(11.9)$ & $25(16.9)$ & $90(13.3)$ \\
\hline Headache & $25(14.7)$ & $47(13.0)$ & $15(10.1)$ & $87(12.8)$ \\
\hline Weight increased & $23(13.5)$ & $38(10.5)$ & $10(6.8)$ & $71(10.5)$ \\
\hline Anxiety & $10(5.9)$ & $36(10.0)$ & $12(8.1)$ & $58(8.5)$ \\
\hline Tremor & $17(10.0)$ & $19(5.3)$ & $11(7.4)$ & $47(6.9)$ \\
\hline Extrapyramidal disorder & $11(6.5)$ & $22(6.1)$ & $12(8.1)$ & $45(6.6)$ \\
\hline Schizophrenia & $11(6.5)$ & $12(3.3)$ & $16(10.8)$ & $39(5.7)$ \\
\hline Nausea & $12(7.1)$ & $20(5.5)$ & $6(4.1)$ & $38(5.6)$ \\
\hline Restlessness & $13(7.6)$ & $17(4.7)$ & $8(5.4)$ & $38(5.6)$ \\
\hline Dyspepsia & $9(5.3)$ & $18(5.0)$ & $10(6.8)$ & $37(5.4)$ \\
\hline Nasopharyngitis & $10(5.9)$ & $19(5.3)$ & $5(3.4)$ & $34(5.0)$ \\
\hline Blood creatine phosphokinase increased & $7(4.1)$ & $17(4.7)$ & $9(6.1)$ & $33(4.9)$ \\
\hline Dizziness & $8(4.7)$ & $18(5.0)$ & $7(4.7)$ & $33(4.9)$ \\
\hline Psychotic disorder & $4(2.4)$ & $13(3.6)$ & $13(8.8)$ & $30(4.4)$ \\
\hline Constipation & $8(4.7)$ & $18(5.0)$ & $2(1.4)$ & $28(4.1)$ \\
\hline Somnolence & $6(3.5)$ & $11(3.0)$ & $9(6.1)$ & $26(3.8)$ \\
\hline Dry mouth & $5(2.9)$ & $5(1.4)$ & $11(7.4)$ & $21(3.1)$ \\
\hline Back pain & $2(1.2)$ & $18(5.0)$ & $1(0.7)$ & $21(3.1)$ \\
\hline
\end{tabular}

${ }^{2}$ One cariprazine $9 \mathrm{mg} / \mathrm{d}$ patient had an AE resulting in discontinuation that was previously categorized as withdrawal of consent

Treatment-emergent akathisia (BARS baseline $\leq 2$ and postbaseline $>2$ ) and parkinsonism (SAS baseline $\leq 3$ and postbaseline $>3$ ) were reported in a greater percentage of patients in the $1.5-3 \mathrm{mg} / \mathrm{d}$ dose group than in the higher dose groups.

\section{Clinical laboratory and additional safety parameters}

A summary of mean changes from lead-in baseline clinical laboratory values and safety parameters is presented in Table 5.

Overall, changes in serum chemistry and hematology parameters were not clinically meaningful. Mean prolactin levels decreased in all dose groups. Clinically insignificant increases in alanine aminotransferase (ALT) and aspartate aminotransferase (AST), and clinically insignificant decreases in alkaline phosphatase were observed, with no dose-response relationship seen across groups. Two patients discontinued due to aminotransferase increases (ALT and AST $=1$ patient each in the $4.5-6 \mathrm{mg} / \mathrm{d}$ and $9 \mathrm{mg} / \mathrm{d}$ groups); 1 patient in the $4.5-6 \mathrm{mg} / \mathrm{d}$ group discontinued due to an increase in bilirubin. No patient met the criteria for Hy's Law (ALT or AST $\geq 3 \times$ upper limit of normal [ULN] concurrent with total bilirubin $\geq 2 \times$ ULN and alkaline phosphatase $<2 \times$ ULN).

Overall, mean creatine phosphokinase (CPK) levels increased during open-label treatment with cariprazine, with the largest increase seen in the $9 \mathrm{mg} / \mathrm{d}$ group. Large standard deviations in all groups suggest large fluctuations in CPK levels over time. One patient each in the 
Table 4 Extrapyramidal Symptoms (Safety Population)

\begin{tabular}{|c|c|c|c|c|}
\hline & $\begin{array}{l}\text { Cariprazine } \\
1.5-3 \mathrm{mg} / \mathrm{d} \\
n=170\end{array}$ & $\begin{array}{l}\text { Cariprazine } \\
4.5-6 \mathrm{mg} / \mathrm{d} \\
n=361\end{array}$ & $\begin{array}{l}\text { Cariprazine } \\
9 \mathrm{mg} / \mathrm{d} \\
n=148\end{array}$ & $\begin{array}{l}\text { Cariprazine } \\
\text { Overall } \\
N=679\end{array}$ \\
\hline \multicolumn{5}{|l|}{ Discontinuation due to EPS-related TEAEs, n (\%) } \\
\hline Any EPS including akathisia and restlessness & $7(4.1)$ & $4(1.1)$ & $1(0.7)$ & $12(1.8)$ \\
\hline Any EPS excluding akathisia and restlessness & $3(1.8)$ & $3(0.8)$ & $1(0.7)$ & $7(1.0)$ \\
\hline \multicolumn{5}{|l|}{$\begin{array}{l}\text { Incidence of common EPS-related TEAEs ( } \geq 5 \text { of } \\
\text { patients in any group), } n(\%)^{\mathrm{a}}\end{array}$} \\
\hline Akathisia & $40(23.5)$ & $45(12.5)$ & $20(13.5)$ & $105(15.5)$ \\
\hline Tremor & $17(10.0)$ & $19(5.3)$ & $11(7.4)$ & $47(6.9)$ \\
\hline Restlessness & $13(7.6)$ & $17(4.7)$ & $8(5.4)$ & $38(5.6)$ \\
\hline Extrapyramidal disorder & $11(6.5)$ & $22(6.1)$ & $12(8.1)$ & $45(6.6)$ \\
\hline \multicolumn{5}{|l|}{ EPS rating scales, mean change $(S D)^{b}$} \\
\hline AIMS total score & $0.1(1.5)$ & $0.0(1.5)$ & $0.1(1.6)$ & $0.0(1.5)$ \\
\hline BARS total score & $0.3(1.7)$ & $-0.1(0.9)$ & $0.1(1.1)$ & $0.1(1.2)$ \\
\hline SAS total score & $0.4(3.0)$ & $-0.3(1.7)$ & $0.1(1.6)$ & $0.0(2.1)$ \\
\hline \multicolumn{5}{|l|}{$\begin{array}{l}\text { Patients with treatment-emergent akathisia or } \\
\text { parkinsonism, n/N1 }(\%)^{\mathrm{a}, \mathrm{c}}\end{array}$} \\
\hline Akathisia (BARS baseline $\leq 2$ and postbaseline $>2$ ) & $40 / 162(24.7)$ & $55 / 360(15.3)$ & 24/148 (16.2) & $119 / 670(17.8)$ \\
\hline Parkinsonism (SAS baseline $\leq 3$ and postbaseline $>3$ ) & 25/162 (15.4) & $30 / 360(8.3)$ & $17 / 148(11.5)$ & $72 / 670(10.7)$ \\
\hline \multicolumn{5}{|c|}{$\begin{array}{l}\text { The preferred terms for EPS-related AEs are akathisia, bradykinesia, cogwheel rigidity, drooling, dyskinesia, dystonia, extrapyramidal disorder, hypokinesia, masked } \\
\text { facies, muscle rigidity, muscle tightness, musculoskeletal stiffness, oculogyric crisis, oromandibular dystonia, parkinsonism, restlessness, salivary hypersecretion, } \\
\text { tardive dyskinesia, tongue spasm, tremor, trismus, and torticollis } \\
\text { AIMS Abnormal Involuntary Movement Scale, BARS Barnes Akathisia Rating Scale, EPS Extrapyramidal symptoms, TEAE Treatment-emergent adverse event, SAS } \\
\text { Simpson-Angus Scale } \\
\text { aAny time during open-label treatment } \\
\text { bMean change from baseline to end of open-label treatment }\end{array}$} \\
\hline
\end{tabular}

$1.5-3 \mathrm{mg} / \mathrm{d}$ group and the $9 \mathrm{mg} / \mathrm{d}$ group discontinued due to clinically significant changes in CPK.

CPK $>1000 \mathrm{U} / \mathrm{L}$ was noted in 58 of 664 (8.7\%) patients; elevations meeting this criterion resolved during the study for $83.1 \%$ of patients. CPK $>1000 \mathrm{U} / \mathrm{L}$ with concurrent positive urine myoglobin was also observed in 5 patients. CPK $>5000 \mathrm{U} / \mathrm{L}$ was seen in 8 of 664 (1.2\%) patients. Observed CPK elevations were not associated with altered renal function or renal failure.

\section{Metabolic parameters}

Mean total, low-density lipoprotein (LDL), and highdensity lipoprotein (HDL) cholesterol levels decreased in all dose groups; no dose-response relationship was observed for metabolic parameters. Clinically relevant shifts from normal/borderline baseline values to high values at the end of treatment for total cholesterol and fasting triglycerides occurred in a similar percentage of patients across dose groups; shifts from normal to high levels in fasting glucose occurred slightly more frequently in the $4.5-6 \mathrm{mg} / \mathrm{d}$ and the $6-12 \mathrm{mg} / \mathrm{d}$ dose groups than in the $1.5-3 \mathrm{mg} / \mathrm{d}$ group.

The percentage of patients with $\geq 7 \%$ increase in body weight was similar in the $1.5-3 \mathrm{mg} / \mathrm{d}$ and $4.5-6 \mathrm{mg} / \mathrm{d}$ dose groups, and slightly lower for patients in the $9 \mathrm{mg} / \mathrm{d}$ group. Of patients who experienced a $\geq 7 \%$ increase in body weight, $34 \%$ were in normal body mass index (BMI) categories at baseline $(\mathrm{BMI}>18.5$ and $<25)$ or underweight (BMI $<18.5$ ); increase in body weight $\geq 7 \%$ occurred in $27.6 \%$ in the overweight category (BMI 25 to $<30$ ) and $16.3 \%$ of patients in the obese category (BMI $\geq 30$ ). Body weight decrease $\geq 7 \%$ was reported with greater frequency in the $9 \mathrm{mg} / \mathrm{d}$ dose group than in the $1.5-3 \mathrm{mg} / \mathrm{d}$ or $4.5-6 \mathrm{mg} / \mathrm{d}$ dose groups.

\section{Cardiovascular parameters}

Mean changes in cardiovascular parameters, including blood pressure and pulse, were generally not clinically significant. Change in diastolic blood pressure was slightly higher in the $9 \mathrm{mg} / \mathrm{d}$ group relative to the lower dose groups, although the increase was not considered clinically significant. Hypertension grouped TEAEs (which included the preferred terms of hypertension and blood pressure increased) occurred in $19(2.8 \%)$ of cariprazine-treated patients overall $(1.5-3 \mathrm{mg} / \mathrm{d}=6$ [3.5\%] patients, $4.5-6 \mathrm{mg} / \mathrm{d}=7[1.9 \%]$ patients, $9 \mathrm{mg} / \mathrm{d}=6$ [4.1\%] patients). More patients in the $9 \mathrm{mg} / \mathrm{d}$ group than in the $1.5-3 \mathrm{mg} / \mathrm{d}$ or $4.5-6 \mathrm{mg} / \mathrm{d}$ groups shifted from 
Table 5 Changes in Clinical Laboratory and Safety Parameters (Safety Population)

\begin{tabular}{|c|c|c|c|c|}
\hline & $\begin{array}{l}\text { Cariprazine } \\
1.5-3 \mathrm{mg} / \mathrm{d} \\
n=170\end{array}$ & $\begin{array}{l}\text { Cariprazine } \\
4.5-6 \mathrm{mg} / \mathrm{d} \\
n=361\end{array}$ & $\begin{array}{l}\text { Cariprazine } \\
9 \mathrm{mg} / \mathrm{d} \\
n=148\end{array}$ & $\begin{array}{l}\text { Cariprazine } \\
\text { Overall } \\
N=679\end{array}$ \\
\hline \multicolumn{5}{|l|}{ Metabolic parameters, mean change (SD) } \\
\hline Total cholesterol, mg/dL & $-2.5(33.0)$ & $-6.1(29.1)$ & $-6.4(33.4)$ & $-5.3(31.1)$ \\
\hline Fasting LDL cholesterol, mg/dL & $-1.1(27.9)$ & $-3.9(25.1)$ & $-4.9(28.0)$ & $-3.5(26.4)$ \\
\hline HDL cholesterol, mg/dL & $-0.9(10.9)$ & $-1.0(11.8)$ & $-0.3(10.5)$ & $-0.8(11.3)$ \\
\hline Fasting triglycerides, mg/dL & $4.4(114.4)$ & $2.2(78.5)$ & $-4.4(74.8)$ & $1.2(87.2)$ \\
\hline Fasting glucose, mg/dL & $5.0(23.6)$ & $3.6(23.9)$ & $6.3(20.9)$ & $4.5(23.2)$ \\
\hline \multicolumn{5}{|l|}{ Clinically relevant shifts in lipid levels and glucose, $\mathrm{n} / \mathrm{N1}^{\mathrm{a}}$ (\%) } \\
\hline $\begin{array}{l}\text { Total cholesterol, normal/borderline (<240 mg/dL) } \\
\text { to high ( } \geq 240 \mathrm{mg} / \mathrm{dL})\end{array}$ & $6 / 143(4.2)$ & $11 / 328(3.4)$ & $6 / 132(4.5)$ & 23/603 (3.8) \\
\hline $\begin{array}{l}\text { Fasting LDL cholesterol, normal/borderline (<160 mg/dL) } \\
\text { to high ( } \geq 160 \mathrm{mg} / \mathrm{dL})\end{array}$ & $4 / 126(3.2)$ & $5 / 325(1.5)$ & $7 / 133(5.3)$ & $16 / 584(2.7)$ \\
\hline HDL cholesterol, normal ( $\geq 40 \mathrm{mg} / \mathrm{dL})$ to low ( $<40 \mathrm{mg} / \mathrm{dL})$ & $13 / 120(10.8)$ & $45 / 280(16.1)$ & 10/107 (9.3) & $68 / 507(13.4)$ \\
\hline $\begin{array}{l}\text { Fasting triglycerides, normal/borderline (<200 mg/dL) } \\
\text { to high ( } \geq 200 \mathrm{mg} / \mathrm{dL})\end{array}$ & 10/119 (8.4) & 24/301 (8.0) & 13/119 (10.9) & $47 / 539(8.7)$ \\
\hline Fasting glucose, normal (<100 mg/dL) to high ( $\geq 126 \mathrm{mg} / \mathrm{dL}$ ) & $3 / 117(2.6)$ & $11 / 270(4.1)$ & $5 / 110(4.5)$ & 19/497 (3.8) \\
\hline \multicolumn{5}{|l|}{ Body weight } \\
\hline Body weight change, kg, mean (SD) & $2.38(4.96)$ & $1.61(5.43)$ & $0.64(5.76)$ & $1.58(5.42)$ \\
\hline$\geq 7 \%$ increase from baseline, $\mathrm{n} / \mathrm{N}^{\mathrm{a}}{ }^{(\%)}$ & $47 / 161(29.2)$ & $101 / 360(28.1)$ & $34 / 148(23.0)$ & 182/669 (27.2) \\
\hline$\geq 7 \%$ decrease from baseline, $\mathrm{n} / \mathrm{N} 1^{\mathrm{a}}(\%)$ & 12/161 (7.5) & $37 / 360(10.3)$ & 24/148 (16.2) & $73 / 669(10.9)$ \\
\hline \multicolumn{5}{|l|}{ Clinical laboratory parameters, mean change (SD) } \\
\hline Prolactin, ng/mL & $-13.6(26.4)$ & $-17.1(47.6)$ & $-13.3(29.3)$ & $-15.4(39.6)$ \\
\hline Alanine aminotransferase, $\mathrm{U} / \mathrm{L}$ & $6.0(44.6)$ & $0.9(20.8)$ & $2.0(16.5)$ & $2.4(27.8)$ \\
\hline Aspartate aminotransferase, $\mathrm{U} / \mathrm{L}$ & $1.8(23.6)$ & $0.1(12.7)$ & $0.1(9.4)$ & $0.5(15.5)$ \\
\hline Alkaline phosphatase, U/L & $-0.6(13.2)$ & $-4.4(32.7)$ & $-1.4(16.5)$ & $-2.8(26.1)$ \\
\hline Total bilirubin, mg/dL & $0.01(0.27)$ & $0.03(0.30)$ & $0.02(0.24)$ & $0.02(0.28)$ \\
\hline Creatine phosphokinase, U/L & $-12.5(218.2)$ & 23.5 (290.6) & $40.2(239.0)$ & $18.5(264.0)$ \\
\hline \multicolumn{5}{|l|}{ Cardiovascular parameters, mean change (SD) } \\
\hline Systolic blood pressure, mmHg & $0.6(11.6)$ & $1.0(11.1)$ & $0.9(11.8)$ & $0.9(11.3)$ \\
\hline Diastolic blood pressure, $\mathrm{mmHg}$ & $0.9(8.6)$ & $0.0(8.5)$ & $1.3(8.9)$ & $0.5(8.6)$ \\
\hline Pulse, bpm & $-2.0(12.4)$ & $-1.7(12.0)$ & $-2.7(11.4)$ & $-2.0(12.0)$ \\
\hline \multicolumn{5}{|l|}{ Electrocardiogram } \\
\hline Ventricular heart rate, bpm & $-2.0(14.3)$ & $0.0(14.7)$ & $-1.7(13.5)$ & $-0.9(14.3)$ \\
\hline QRS interval, msec & $0.9(6.5)$ & $0.8(8.2)$ & $-0.8(7.4)$ & $0.5(7.7)$ \\
\hline PR interval, msec & $-2.3(14.3)$ & $-0.1(15.1)$ & $-0.4(15.0)$ & $-0.7(14.9)$ \\
\hline QT interval, msec & $4.3(26.7)$ & $-1.5(30.5)$ & $0.6(28.1)$ & $0.4(29.1)$ \\
\hline QTcB interval, msec & $-1.3(22.4)$ & $-1.5(22.1)$ & $-3.7(21.0)$ & $-1.9(21.9)$ \\
\hline QTcF interval, msec & $0.7(16.2)$ & $-1.5(18.0)$ & $-2.2(17.1)$ & $-1.1(17.4)$ \\
\hline Shift from normotensive to Stage I or Stage I| hypertension, $\mathrm{n}(\%)^{\mathrm{b}}$ & 2/63 (3.2) & $3 / 122(2.5)$ & $4 / 46(8.7)$ & 9/231 (3.9) \\
\hline
\end{tabular}

HDL High-density lipoprotein, LDL Low-density lipoprotein, QTCB QT interval corrected for heart rate using the Bazett formula, QTcF QT interval corrected for heart rate using the Fridericia formula

${ }^{a} \mathrm{~N} 1$ is the subset of patients who met baseline criteria and had $\geq 1$ nonmissing postbaseline value during open-label treatment; $\mathrm{n}$ is the subset of $\mathrm{N} 1$ who met the criteria during the open-label treatment period

${ }^{\mathrm{b}}$ Normotensive: systolic blood pressure $<120 \mathrm{mmHg}$ and diastolic blood pressure $<80 \mathrm{mmHg}$; stage I hypertension: systolic blood pressure $140-159 \mathrm{mmHg}$ or diastolic blood pressure $90-99 \mathrm{mmHg}$; Stage II hypertension: systolic blood pressure $\geq 160 \mathrm{mmHg}$ or diastolic blood pressure $\geq 100 \mathrm{mmHg}$ 
normotensive levels to stage I or II hypertension. Overall, no cardiovascular TEAE was reported in $\geq 2 \%$ of patients and there was no mean increase in QTc interval. A > $60 \mathrm{msec}$ increase in QTcB value occurred in 7 patients $(1.0 \%)$ overall, while a $>60 \mathrm{msec}$ increase in QTcF value occurred in 2 patients $(0.3 \%)$ overall. Three patients $(0.4 \%)$ had a postbaseline $\mathrm{QTcB}$ value $>500 \mathrm{msec}$; one of these patients $(0.2 \%)$ also had a postbaseline QTcF value $>500$ msec.

Orthostatic hypotension $(\geq 20 \mathrm{mmHg}$ reduction in systolic blood pressure or $\geq 10 \mathrm{mmHg}$ reduction in diastolic blood pressure while changing from a supine to standing position) was reported in 131/645 (20.3\%) of patients overall $(1.5-3 \mathrm{mg} / \mathrm{d}=33 / 155$ [21.3\%] patients; $4.5-6 \mathrm{mg} / \mathrm{d}=66 / 348$ [19.0\%]; $9 \mathrm{mg} / \mathrm{d}=32 / 142$ [22.5\%]).

\section{Suicidality}

For patients in RGH-MD-11, treatment-emergent suicidal ideation based on C-SSRS assessment was noted in 16 (2.8\%) cariprazine-treated patients overall $(1.5-3 \mathrm{mg} / \mathrm{d}=4$ [3.0\%]; $4.5-6 \mathrm{mg} / \mathrm{d}=7$ [2.3\%]; $9 \mathrm{mg} / \mathrm{d}=5$ [3.4\%]); the majority of C-SSRS suicidal ideation was in the least severe category ("wish to be dead," no active suicidal thoughts or intent). C-SSRS suicidal behavior was not noted in any cariprazine-treated patient. In RGH-MD-17, no mean change (0.0) in STS scores was observed; among the 7 patients with non-zero STS total scores, no TEAEs related to suicidal ideation or suicidal behavior were reported. TEAEs of suicidal ideation were reported in $4(0.6 \%)$ patients overall $(1.5-3 \mathrm{mg} / \mathrm{d}=2[1.2 \%] ; 4.5-6 \mathrm{mg} / \mathrm{d}=1$ $[0.3 \%] ; 9 \mathrm{mg} / \mathrm{d}=1[0.7 \%])$. A completed suicide occurred in a patient in the $4.5-6 \mathrm{mg} / \mathrm{d}$ dose group; the event was not considered related to cariprazine.

\section{Ophthalmologic parameters}

No clinically significant changes were reported on ophthalmologic examination. Blurred vision was the most common ocular AE (1.5-3 mg/d: $2.4 \%$; $4.5-6 \mathrm{mg} / \mathrm{d}: 1.7 \%$; $9 \mathrm{mg} / \mathrm{d}: 1.4 \%)$. One patient $(0.6 \%)$ in the $1.5-3 \mathrm{mg} / \mathrm{d}$ group had an $\mathrm{AE}$ of cataract in the left eye, which was reported on day 337 and considered resolved 38 days after the last dose of cariprazine. Due to its unilateral nature and rapid reversal, it was considered by an independent ophthalmologist to be unrelated to cariprazine treatment. No ocular SAEs were reported.

\section{Summary of efficacy}

Mean (SD) change from the extension study baseline to the end of study in PANSS total score was -4.5 (12.51) for patients in the $1.5-3 \mathrm{mg} / \mathrm{d}$ dose group, -7.1 (12.91) for patients in the 4.5-6 mg/d dose group, -2.4 (16.03) for patients in the $9-12 \mathrm{mg} / \mathrm{d}$ dose group, and -5.4 (13.70) in the overall cariprazine dose group. Although the primary objective of these open-label studies was to evaluate the long-term safety and tolerability of cariprazine, PANSS total score decreases (improvement) were sustained, suggesting that there was no worsening of schizophrenia symptoms during long-term cariprazine treatment.

\section{Discussion}

Pooled analyses of data from these 2 open-label, 48-week extension studies supported previous findings from studies investigating safety and tolerability of cariprazine in patients with acute exacerbation of schizophrenia. These data may approximate safety findings in the recommended dose range for cariprazine in schizophrenia since almost $80 \%$ of patients were in modal daily dose groups in the $1.5-6 \mathrm{mg} / \mathrm{d}$ range $(1.5-3 \mathrm{mg} / \mathrm{d}=170$ patients; $4.5-6 \mathrm{mg} / \mathrm{d}=361 \mathrm{pa}-$ tients) as opposed to a higher dose ( $9 \mathrm{mg} / \mathrm{d}=148$ patients). Approximately $40 \%$ of cariprazine-treated patients overall completed the study, with higher completion rates observed in the approved daily dose range $(1.5-6 \mathrm{mg} / \mathrm{d})$ than in the $9 \mathrm{mg} / \mathrm{d}$ modal daily dose group. The overall completion rate for open-label cariprazine was comparable to rates seen in similarly designed safety studies for other atypical antipsychotics including lurasidone (12-month completion $=36.7 \%$ [33]), iloperidone (25-week completion $=41.6 \%$ [34], and ziprasidone (12-month completion $=36.9 \%$ [35]).

At least 1 TEAE was reported by most patients in the long-term schizophrenia studies; approximately $70 \%$ were considered mild or moderate and approximately $60 \%$ were considered related to treatment. Discontinuations due to AEs occurred more frequently in the $1.5-3 \mathrm{mg} / \mathrm{d}$ and the $9 \mathrm{mg} / \mathrm{d}$ dose groups than in the $4.5-6 \mathrm{mg} / \mathrm{d}$ group, which is counterintuitive and may have been the result of a patient selection bias. The only AEs that led to discontinuation of $\geq 2 \%$ of patients in any group were akathisia, worsening of schizophrenia, and worsening of psychotic disorder.

Cariprazine has a complex pharmacokinetic profile, with 2 major active metabolites, desmethyl cariprazine and didesmethyl cariprazine. The effective half-life for the total active moieties, which takes into account cariprazine and the 2 major active metabolites, is approximately 1 week [19]. The long half-life triggered initial concern that cariprazine could potentially be associated with dose-related adverse effects and accumulation of the parent drug and active metabolites beyond levels needed for effectiveness. Specifically, post hoc analyses of safety findings from the short-term controlled cariprazine studies in schizophrenia [20-22] showed a dose-response relationship for some TEAEs and clinical laboratory values including akathisia, extrapyramidal disorder, CPK elevations, transaminase elevations, and increases in blood pressure [36]. However, investigating the incidence of safety events in modal daily dose groups helped alleviate concerns about the 
pharmacokinetics of cariprazine since the risk of these events was determined to be lower at doses $\leq 6 \mathrm{mg} / \mathrm{d}$ than at doses $\geq 9 \mathrm{mg} / \mathrm{d}$. As such, better tolerability observed at lower cariprazine doses helped establish the FDArecommended dose range of $1.5-6 \mathrm{mg} / \mathrm{d}$ for treating schizophrenia. Results from the post hoc analyses of longterm cariprazine safety data presented here found no new safety concerns related to the pharmacokinetic profile and long half-life of cariprazine. Additionally, there was no evidence of delayed resolution of adverse effects after cariprazine discontinuation. AEs that resulted in discontinuation resolved in $80 \%$ of patients, with the median time to resolution of 12 days; the median time to resolution of akathisia/restlessness was 15 days.

The only TEAES reported in $\geq 10 \%$ of patients overall were akathisia, insomnia, headache and weight increased; anxiety and tremor were reported in $\geq 10 \%$ in 1 of the dose groups within the FDA-recommended dose range and worsening of schizophrenia was reported in $11 \%$ of patients in the $9 \mathrm{mg} / \mathrm{d}$ dose group. The incidence of treatment-related sedation and somnolence, which can interfere with quality of life in a substantial minority of patients with schizophrenia [6], was generally low $(3 \%-4 \%)$ and no dose response was observed for these TEAEs. SAEs were nearly twice as likely to occur at the highest dose $(9 \mathrm{mg} / \mathrm{d})$ than in the FDA-recommended dose range $(1.5-6 \mathrm{mg} / \mathrm{d})$, although the most commonly reported SAEs (worsening of schizophrenia and psychotic disorder) were reported in $<5 \%$ of patients overall.

Weight gain, dyslipidemia, and glucose dysregulation, which contribute to cardiovascular risk in patients with schizophrenia, are common treatment-related side effects of atypical antipsychotics [37]. Consequently, the effect of cariprazine on these parameters is an important long-term safety consideration. In these post hoc analyses, no dose-response relationship was observed for metabolic parameters and there were no mean increases from baseline in lipid parameters over time with longterm cariprazine treatment. Mean changes from baseline to the end of long-term treatment for fasting glucose $(4.5 \mathrm{mg} / \mathrm{dL})$ and the proportion of patients with treatment-emergent significant changes in lipid parameters were similar to changes observed in the 6-week controlled studies [36]; however, the incidence of significant treatment-emergent changes in fasting glucose tended to increase over time with long-term treatment. The overall mean change from baseline in weight at the end of longterm open-label treatment was small $(1.58 \mathrm{~kg})$ and only slightly greater than the weight change observed in the 6-week controlled cariprazine studies in schizophrenia $(\sim 1 \mathrm{~kg})$ [20-22]. Although weight increases $\geq 7 \%$ were observed in $23 \%-29 \%$ of cariprazine-treated patients across the modal dose groups during long-term treatment, no weight gain event was an SAE or led to study discontinuation. Unlike data from the 6-week controlled trials in schizophrenia, which showed a dose-response relationship for weight gain in cariprazine-treated patients, no consistent pattern of weight-related changes was seen among the dose groups in the pooled 48-week dataset. Weight decreases $\geq 7 \%$ occurred in $11 \%$ of cariprazine-treated patients overall, with an apparent dose-response relationship observed $(1.5-3 \mathrm{mg} / \mathrm{d}=7.5 \%$; $4.5-6 \mathrm{mg} / \mathrm{d}=10.3 \%$; $9 \mathrm{mg} / \mathrm{d}=16.2 \%$ ).

Cardiac AEs were minimal among all dose groups, with no individual TEAE occurring in $\geq 2 \%$ of cariprazine-treated patients. There was no mean increase in QTc interval overall; 3 patients had a postbaseline QTcB value $>500 \mathrm{msec}$, one of whom also had a postbaseline QTcF value $>500 \mathrm{msec}$. Shift from normotensive blood pressure to Stage I or Stage II hypertension occurred in a higher percentage of patients in the 9-12 $\mathrm{mg} / \mathrm{d}$ group than in the lower dose groups.

Akathisia is one of the most commonly recognized treatment-emergent effects associated with antipsychotic treatment, although it is generally reported to be less prevalent with second-generation antipsychotics than with first-generation agents [38-40]. It remains a clinically significant adverse effect however, as shown by results from the Clinical Antipsychotic Trials of Intervention Effectiveness (CATIE) trial, which found that the percentage of patients with schizophrenia who developed akathisia was not significantly different for the intermediate-potency first-generation antipsychotic perphenazine and 4 atypical antipsychotics (olanzapine, quetiapine, risperidone, ziprasidone) [41]. Although the distress of antipsychotic-induced akathisia can be severe enough to adversely affect treatment adherence and long-term patient outcomes [38], it is routinely managed along with other disease-induced or drug-induced symptoms in clinical practice [39].

Akathisia was the most commonly observed TEAE in this pooled 48-week dataset; most occurrences were mild to moderate in severity, considered related to treatment, and rarely led to treatment discontinuation. The first occurrence of akathisia was generally reported within the first 6 weeks of treatment and it resulted in few discontinuations overall $(0.9 \%)$ or in the modal daily dose groups $(0$ [9 mg/d group] to $2.9 \%$ [1.5-3 mg/d group]). In long-term cariprazine treatment, the majority of patients used medication to manage symptoms of akathisia/restlessness, regardless of the severity of the event. Along with the low rate of discontinuation due to akathisia, this suggests that akathisia was managed by most patients while continuing treatment with cariprazine.

Ocular safety was evaluated in the long-term cariprazine studies in patients with schizophrenia in response to ocular findings from preclinical studies in dogs and rats. In these long-term, open-label pooled analysis, blurred vision was 
the most commonly reported ocular AE. One patient in the $1.5-3 \mathrm{mg} / \mathrm{d}$ group had an $\mathrm{AE}$ of cataract that in the judgement of an independent ophthalmologist was not considered a pathological event based on its unilateral nature and rapid reversal, which are atypical of druginduced cataracts. No ocular SAEs were reported. From these analyses, ophthalmologic AEs associated with cariprazine appear to be rare and not likely related to treatment.

These analyses were subject to the limitations inherent in post hoc analyses, as well as the limitations of openlabel study design in which there was no placebo- or active-comparator group. Per the constituent study protocols, safety parameters were not analyzed using inferential statistics. The results of these analyses may have been confounded by a heterogeneous dataset that included patients who had completed a lead-in study as well as patients who were newly enrolled; additionally, patients who continued from a lead-in study may have received either placebo, cariprazine, or aripiprazole. Lack of a randomized study population and the use of modal dose groups may have resulted in patient selection bias. A tolerability bias in favor of patients in the high modal daily dose group may have existed since patients with tolerability issues at lower doses may have been more likely to discontinue the study and less likely to increase their dosage. Conversely, completion rates may have been effected by a bias against patients in the $9 \mathrm{mg} / \mathrm{d}$ dose group in reference to discontinuations due to insufficient therapeutic response, as well as discontinuations due to AEs of schizophrenia and psychotic disorder. These events, which occurred at the greatest frequency in the high dose group, may reflect the propensity to increase the dose in patients who do not respond at a lower dose level, indicating potential treatment resistance. Of note, worsening of the underlying condition, in this case schizophrenia and psychotic disorder, is categorized as an $\mathrm{AE}$ when in actuality it may be an additional indication of poor treatment response or lack of efficacy. Furthermore, worsening of schizophrenia may be a sign of treatment noncompliance or inconsistency, which is a common problem that may lead to worse outcomes in patients with schizophrenia [8].

\section{Conclusion}

In these post hoc pooled analyses of data from 2 longterm open-label studies, treatment with cariprazine was generally safe and well tolerated. Given the distribution of patients across modal daily dose groups, these results support the safety and tolerability of cariprazine within the FDA-recommended dose range of $1.5-6 \mathrm{mg} / \mathrm{d}$ for schizophrenia. Dose-related adverse effects were minimal and no persistent adverse effects after the discontinuation of cariprazine suggest that the complex pharmacokinetics of cariprazine did not appear to affect the long-term safety profile of cariprazine.

\section{Additional file}

Additional file 1: Institutional Review Boards and Independent Ethics Committees. A good clinical practices statement and a table of the Institutional Review Boards (sites in the United States) and Independent Ethics Committees (sites outside of the United States) that approved the protocols. (PDF $166 \mathrm{~kb}$ )

\section{Abbreviations}

AE: Adverse event; AIMS: Abnormal Involuntary Movement Scale; ALT: Alanine aminotransferase; AST: Aspartate aminotransferase; BARS: Barnes Akathisia Rating Scale; BMI: Body mass index; CGI-S: Clinical Global Impressions-Severity of Illness; CPK: Creatine phosphokinase; C-SSRS: Columbia-Suicide Severity Rating Scale; DSM-IV-TR: Diagnostic and Statistical Manual of Mental Disorders, Fourth Edition, Text Revision; ECG: Electrocardiogram; EPS: Extrapyramidal symptoms; HDL: High-density lipoprotein; LDL: Low-density lipoprotein; PANSS: Positive and Negative Syndrome Scale; QTCB: QT interval corrected for heart rate using the Bazett formula; QTCF: QT interval corrected for heart rate using the Fridericia formula; SAE: Serious adverse event; SAS: Simpson-Angus Scale; STS: Suicidality Tracking Scale; TEAE: Treatment-emergent adverse event; ULN: upper limit of normal

\section{Acknowledgements}

Writing assistance and editorial support for this manuscript were provided by Carol Brown, MS, of Prescott Medical Communications Group, Chicago, Illinois, a contractor of Allergan.

\section{Funding}

Supported by funding from Forest Research Institute, Inc., an Allergan affiliate, Jersey City, NJ, USA, and Gedeon Richter Plc, Budapest, Hungary. Forest Laboratories, LLC, an Allergan affiliate, and Gedeon Richter PlC were involved in the study design, collection (via contracted clinical investigator sites), analysis and interpretation of data, and the decision to present these results.

\section{Availability of data and materials}

Allergan will accept and review external scientific research proposals and provide applicable anonymized patient-level data to support external research involving our clinical trial data. Additional information can be found at: http://allerganclinicaltrials.com/PatientDataRequest.htm.

\section{Authors' contributions}

SD and YW were involved in the design and conduct of the study as well as the interpretation of data. $\mathrm{KL}$ contributed to the statistical design of the study, the statistical analysis, and the interpretation of data. IL and GN were involved in the design of the study and interpretation of data. AC contributed to the design and conduct of the study, as well as the interpretation of data. WE contributed to the conduct of the study and the interpretation of data. HN contributed as a clinical expert for data interpretation. All authors participated in the development of the manuscript and approved the final version for submission.

\section{Ethics approval and consent to participate}

The constituent clinical studies were conducted in full compliance with Food and Drug Administration guidelines for good clinical practice and in

accordance with the ethical principles that have their origins in the Declaration of Helsinki. The protocol of each study was approved by an institutional review board at sites in the United States or independent ethics committee at sites outside of the United States (Additional file 1). The studies were conducted in compliance with guidelines for good clinical practice; all patients gave informed written consent to participate. 


\section{Competing interests}

HN has been a consultant for Acadia, Alkermes, Allergan, Boehringer Ingelheim, Grünenthal USA, Inc., Janssen Pharmaceuticals, Inc., Lundbeck, Merck Sharp \& Dohme Corp., Novartis Corporation, Otsuka Pharmaceutical Co., Ltd., Roche/Genentech, Sunovion Pharmaceuticals, Inc., and Vanda Pharmaceuticals; he has served on speakers' bureaus for Acadia, Alkermes, Allergan, Janssen Pharmaceuticals, Inc., Otsuka Pharmaceuticals, Sunovion Pharmaceuticals, Inc. and Vanda; he has received grant/research support from Forest Pharmaceuticals, Inc., Otsuka Pharmaceutical Co., Ltd., and Roche/Genentech. AC has received research grants and consultant/speaker fees from Acadia, Alkermes, Allergan, AstraZeneca, Braeburn Pharmaceuticals, Forum Pharmaceuticals, Janssen (Johnson \& Johnson), Eli Lilly, Lundbeck, Neurocrine, Novartis, Otsuka, Reckitt Benckiser, Sunovion, Takeda, Teva, and Vanda. SD, WE, YW, and $\mathrm{KL}$ acknowledge a potential conflict of interest as employees of Allergan. IL and GN acknowledge a potential conflict of interest as employees of Gedeon Richter PIc.

\section{Publisher's Note}

Springer Nature remains neutral with regard to jurisdictional claims in published maps and institutional affiliations.

\section{Author details}

${ }^{1}$ Saint Louis University, 1438 South Grand Blvd., Suite 105, St. Louis, MO 63104, USA. ²Allergan, Harborside 5, 185 Hudson Street, Jersey City, NJ 07311, USA. ${ }^{3}$ Meridien Research, Inc., 8043 Cooper Creek Boulevard \#107, Bradenton, FL 34201, USA. ${ }^{4}$ Gedeon Richter, PIC, Gyömrői u. 32, Budapest H-1103, Hungary.

Received: 13 March 2017 Accepted: 11 August 2017

Published online: 24 August 2017

\section{References}

1. Goff DC, Cather C, Evins AE, Henderson DC, Freudenreich O, Copeland PM, et al. Medical morbidity and mortality in schizophrenia: guidelines for psychiatrists. J Clin Psychiatry. 2005;66(2):183-94. quiz 47, 273-4

2. Kreyenbuhl J, Buchanan RW, Dickerson FB, Dixon LB. Schizophrenia patient outcomes research $\mathrm{T}$. The schizophrenia patient outcomes research team (PORT): updated treatment recommendations 2009. Schizophr Bull. 2010; 36(1):94-103.

3. Leucht S, Cipriani A, Spineli L, Mavridis D, Orey D, Richter F, et al. Comparative efficacy and tolerability of 15 antipsychotic drugs in schizophrenia: a multipletreatments meta-analysis. Lancet. 2013;382(9896):951-62.

4. Farah A. Atypicality of atypical antipsychotics. Prim Care Companion J Clin Psychiatry. 2005;7(6):268-74.

5. Luft B, Taylor D. A review of atypical antipsychotic drugs versus conventional medication in schizophrenia. Expert Opin Pharmacother. 2006; 7(13):1739-48

6. Kane JM, Sharif ZA. Atypical antipsychotics: sedation versus efficacy. J Clin Psychiatry. 2008:69(Suppl 1):18-31.

7. Higashi K, Medic G, Littlewood K, Diez T, Granstrom O, De Hert M. Medication adherence in schizophrenia: factors influencing adherence and consequences of nonadherence, a systematic literature review. Ther Adv Psychopharmacol. 2013;3(4):200-18.

8. Leucht S, Heres S. Epidemiology, clinical consequences, and psychosocial treatment of nonadherence in schizophrenia. J Clin Psychiatry. 2006;67(Suppl 5):3-8.

9. Kiss B, Horvath A, Nemethy Z, Schmidt E, Laszlovszky I, Bugovics G, et al. Cariprazine ( $\mathrm{RGH}-188)$, a dopamine $\mathrm{D}(3)$ receptor-preferring, $\mathrm{D}(3) / \mathrm{D}(2)$ dopamine receptor antagonist-partial agonist antipsychotic candidate: in vitro and neurochemical profile. J Pharmacol Exp Ther. 2010;333(1):328-40.

10. Gyertyan I, Kiss B, Saghy K, Laszy J, Szabo G, Szabados T, et al. Cariprazine (RGH-188), a potent D3/D2 dopamine receptor partial agonist, binds to dopamine D3 receptors in vivo and shows antipsychotic-like and procognitive effects in rodents. Neurochem Int. 2011;59(6):925-35.

11. Girgis RR, Slifstein M, D'Souza D, Lee Y, Periclou A, Ghahramani P, et al. Preferential binding to dopamine D3 over D2 receptors by cariprazine in patients with schizophrenia using PET with the D3/D2 receptor ligand [(11)C]-(+)-PHNO. Psychopharmacology. 2016;233(19-20):3503-12.

12. Caravaggio F, Blumberger D, Nakajima S, Mulsant B, Graff-Guerrerero A Occupancy of dopamine D3 receptors by aripiprazole in treatment resistant late-life depressed patients depends on length of treatment as evidenced by in vivo imaging with [11C]-(+)-PHNO. Am J Geriatr Psychitary. 2014;22:S83-4.

13. Graff-Guerrero A, Mamo D, Shammi CM, Mizrahi R, Marcon H, Barsoum P, et al. The effect of antipsychotics on the high-affinity state of D2 and D3 receptors: a positron emission tomography study with [11C]-(+)-PHNO. Arch Gen Psychiatry. 2009;66(6):606-15.

14. Mizrahi R, Agid O, Borlido C, Suridjan I, Rusjan P, Houle S, et al. Effects of antipsychotics on D3 receptors: a clinical PET study in first episode antipsychotic naive patients with schizophrenia using [11C]-(+)-PHNO. Schizophr Res. 2011;131(1-3):63-8.

15. Kroeze WK, Hufeisen SJ, Popadak BA, Renock SM, Steinberg S, Ernsberger P, et al. H1-histamine receptor affinity predicts short-term weight gain for typical and atypical antipsychotic drugs. Neuropsychopharmacology. 2003; 28(3):519-26.

16. Reynolds GP. Histamine and antipsychotic drug-induced weight gain. J Psychopharmacol. 2012;26(12):1608-9

17. Richelson E. New antipsychotic drugs: how do their receptor-binding profiles compare? J Clin Psychiatry. 2010;71(9):1243-4.

18. Leung JY, Barr AM, Procyshyn RM, Honer WG, Pang CC. Cardiovascular sideeffects of antipsychotic drugs: the role of the autonomic nervous system. Pharmacol Ther. 2012;135(2):113-22.

19. Nakamura T, Kubota T, Iwakaji A, Imada M, Kapas M, Morio Y. Clinical pharmacology study of cariprazine (MP-214) in patients with schizophrenia (12-week treatment). Drug Des Devel Ther. 2016;10:327-38.

20. Durgam S, Cutler AJ, Lu K, Migliore R, Ruth A, Laszlovszky I, et al. Cariprazine in acute exacerbation of schizophrenia: a fixed-dose, phase 3, randomized, double-blind, placebo- and active-controlled trial. J Clin Psychiatry. 2015; 76(12):e1574-82.

21. Durgam S, Starace A, Li D, Migliore R, Ruth A, Nemeth G, et al. An evaluation of the safety and efficacy of cariprazine in patients with acute exacerbation of schizophrenia: a phase II, randomized clinical trial. Schizophr Res. 2014;152(2-3):450-7.

22. Kane JM, Zukin S, Wang Y, Lu K, Ruth A, Nagy K, et al. Efficacy and safety of cariprazine in acute exacerbation of schizophrenia: results from an international, phase III clinical trial. J Clin Psychopharmacol. 2015;35(4):367-73.

23. Cutler AJ, Durgam S, Wang Y, Migliore R, Lu K, Laszlovszky I, et al. Evaluation of the long-term safety and tolerability of cariprazine in patients with schizophrenia: results from a 1-year open-label study. CNS Spectr. 2017:1-12.

24. Durgam S, Greenberg WM, Li D, Lu K, Laszlovszky I, Nemeth G, et al. Safety and tolerability of cariprazine in the long-term treatment of schizophrenia: results from a 48-week, single-arm, open-label extension study. Psychopharmacology. 2017;234(2):199-209.

25. American Psychiatric Association. Diagnostic and Statistical Manual of Mental Disorders, fourth edition, text revision. Washington, DC: American Psychiatric Association; 2000.

26. Kay SR, Fiszbein A, Opler LA. The positive and negative syndrome scale (PANSS) for schizophrenia. Schizophr Bull. 1987;13(2):261-76.

27. Guy W. Clinical Global Impressions. In: Guy W, editor. ECDEU assessment manual for psychopharmacology: publication ADM 76-338. Rockville: National Institute of Mental Health, Psychopharmacology Research Branch; 1976. p. 217-22.

28. Posner K, Brown GK, Stanley B, Brent DA, Yershova KV, Oquendo MA, et al. The Columbia-suicide severity rating scale: initial validity and internal consistency findings from three multisite studies with adolescents and adults. Am J Psychiatry. 2011;168(12):1266-77.

29. Coric V, Stock EG, Pultz J, Marcus R, Sheehan DV. Sheehan Suicidality tracking scale (Sheehan-STS): preliminary results from a multicenter clinical trial in generalized anxiety disorder. Psychiatry (Edgmont). 2009;6(1):26-31.

30. Barnes TR. A rating scale for drug-induced akathisia. Br J Psychiatry. 1989;154:672-6.

31. Guy W. The abnormal movement scale. ECDEU assessment manual for psychopharmacology, DHEW publication no. 76-338. Rockville: National Institute of Mental Health; 1976. p. 218-22.

32. Simpson GM, Angus JW. A rating scale for extrapyramidal side effects. Acta Psychiatr Scand Suppl. 1970;212:11-9

33. Correll CU, Cucchiaro J, Silva R, Hsu J, Pikalov A, Loebel A. Long-term safety and effectiveness of lurasidone in schizophrenia: a 22-month, open-label extension study. CNS Spectr. 2016;21(5):393-402.

34. Cutler AJ, Kalali AH, Mattingly GW, Kunovac J, Meng X. Long-term safety and tolerability of iloperidone: results from a 25-week, open-label extension trial. CNS Spectr. 2013;18(1):43-54. 
35. Sciarretta A, Piazzi G. Long-term safety of ziprasidone in schizophrenic patients: an open trial. Eur Rev Med Pharmacol Sci. 2012;16(15):2113-9.

36. Earley W, Durgam S, Lu K, Laszlovszky I, Debelle M, Kane JM. Safety and tolerability of cariprazine in patients with acute exacerbation of schizophrenia: a pooled analysis of four phase II/III randomized, doubleblind, placebo-controlled studies. [published online ahead of print July 7 , 2017]. Int Clin Psychopharmacol. Available at: http://journals.Iww.com/ intclinpsychopharm/Abstract/publishahead/Safety_and_tolerability_of cariprazine_in_patients.99599.aspx.

37. Newcomer JW. Antipsychotic medications: metabolic and cardiovascular risk. J Clin Psychiatry. 2007;68(Suppl 4):8-13.

38. Kane JM, Barnes TR, Correll CU, Sachs G, Buckley P, Eudicone J, et al. Evaluation of akathisia in patients with schizophrenia, schizoaffective disorder, or bipolar I disorder: a post hoc analysis of pooled data from short- and long-term aripiprazole trials. J Psychopharmacol. 2010;24(7):1019-29.

39. Kane JM, Fleischhacker WW, Hansen L, Perlis R, Pikalov A 3rd, AssuncaoTalbott S. Akathisia: an updated review focusing on second-generation antipsychotics. J Clin Psychiatry. 2009;70(5):627-43.

40. Kumar R, Sachdev PS. Akathisia and second-generation antipsychotic drugs. Curr Opin Psychiatry. 2009;22(3):293-9.

41. Lieberman JA, Stroup TS, McEvoy JP, Swartz MS, Rosenheck RA, Perkins DO, et al. Effectiveness of antipsychotic drugs in patients with chronic schizophrenia. N Engl J Med. 2005;353(12):1209-23.

\section{Submit your next manuscript to BioMed Central} and we will help you at every step:

- We accept pre-submission inquiries

- Our selector tool helps you to find the most relevant journal

- We provide round the clock customer support

- Convenient online submission

- Thorough peer review

- Inclusion in PubMed and all major indexing services

- Maximum visibility for your research

Submit your manuscript at www.biomedcentral.com/submit 